\title{
Penoscrotal transposition for pre-penile scrotum in Hypospadias: Analysis of timing and outcome
}

\author{
Authors \\ Dr Vivek Parameswara Sarma, Dr Sunil S Menon \\ Department of Paediatric Surgery, SAT Hospital \\ Govt Medical College, Thiruvananthapuram
}

\section{Introduction}

Pre-penile scrotum (also referred to as Penoscrotal transposition) represents a wide spectrum of abnormality varying from mild to severe. It is usually associated with proximal hypospadias and chordee. [Refer Figures 1-4].

\section{Aim}

To analyse the timing of surgery and post operative outcome of Penoscrotal transposition procedure for pre penile scrotum in Hypospadias. The postoperative complications when prepenile scrotum was corrected as a primary procedure/secondary procedure were also compared.

\section{Materials and Methods}

20 patients who underwent the Glenn - Anderson Penoscrotal transposition correction during the period of January 2011 to January 2016. Age group ranged from 18 months to 11 years.

Nine patients underwent the surgery as a primary procedure while 11 other patients underwent the surgery after previous procedures performed elsewhere.
Modified Glenn Anderson procedure [Refer Figure $5,6]$, separating the rotation flaps by a narrow strip of dorsal skin was performed in all patients.

The available follow up was in the range of 3 months to 2 years.

Table 1: Age of the patient at surgery

\begin{tabular}{|c|c|}
\hline Age (years) & $\mathbf{n = 2 0}$ \\
\hline $1-2$ & 2 \\
\hline $2-4$ & 7 \\
\hline $4-6$ & 6 \\
\hline $6-8$ & 3 \\
\hline$>8$ & 2 \\
\hline
\end{tabular}

Table 2: Type of Hypospadias associated with prepenile scrotum

\begin{tabular}{|l|c|}
\hline Type of Hypospadias & $\mathbf{n = 2 0}$ \\
\hline Mid penile & 1 \\
\hline Proximal penile & 6 \\
\hline Penoscrotal & 11 \\
\hline Perineal & 2 \\
\hline
\end{tabular}

Table 3: The sequence of performance of correction of prepenile scrotum

\begin{tabular}{|l|c|}
\hline $\begin{array}{l}\text { Sequence of Peno-scrotal transposition } \\
\text { correction }\end{array}$ & $\mathbf{n = 2 0}$ \\
\hline As the first procedure & 9 \\
\hline After Stage 1 Hypospadias repair & 7 \\
\hline After failed urethroplasty & 2 \\
\hline After completed urethroplasty & 2 \\
\hline
\end{tabular}


Table 4: Postoperative complications after surgery for prepenile scrotum

\begin{tabular}{|l|c|c|}
\hline Complications & $\begin{array}{c}\text { Primary } \\
(\mathbf{n}=\mathbf{9})\end{array}$ & $\begin{array}{c}\text { Secondary } \\
(\mathbf{n}=\mathbf{1 1})\end{array}$ \\
\hline Severe penile oedema & 1 & 4 \\
\hline Skin ischemia / superficial necrosis & - & 1 \\
\hline Surgical site infection & - & 2 \\
\hline Suture dehiscence & - & 2 \\
\hline Urethral injury & - & - \\
\hline Testicular injury & - & - \\
\hline
\end{tabular}

\section{Results}

An excellent cosmetic outcome was possible in all cases that underwent a primary correction of penoscrotal transposition. It was observed that there was an increased incidence of complications when the same correction was performed secondarily.

Preliminary correction of pre penile scrotum permitted more precise correction of chordee and urethroplasty later. The testes which are usually displaced superiorly could be fixed inferiorly along with the scrotal elongation achieved by the procedure. Also, the correction of bifid scrotum, if present, is possible simultaneously

There were no intra operative complications like injury to testes/urethra, which are possible when combined with chordee correction / Urethroplasty. The avoidance of the incision surrounding the entire base of penis decreases post operative skin complications and permits better healing of neourethra later.

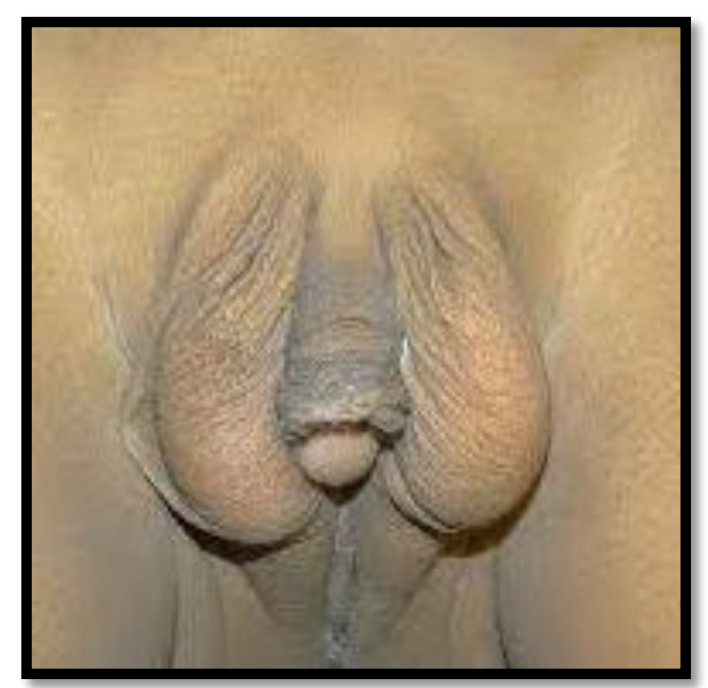

Figure 1 Varying degrees of severity of prepenile scrotum

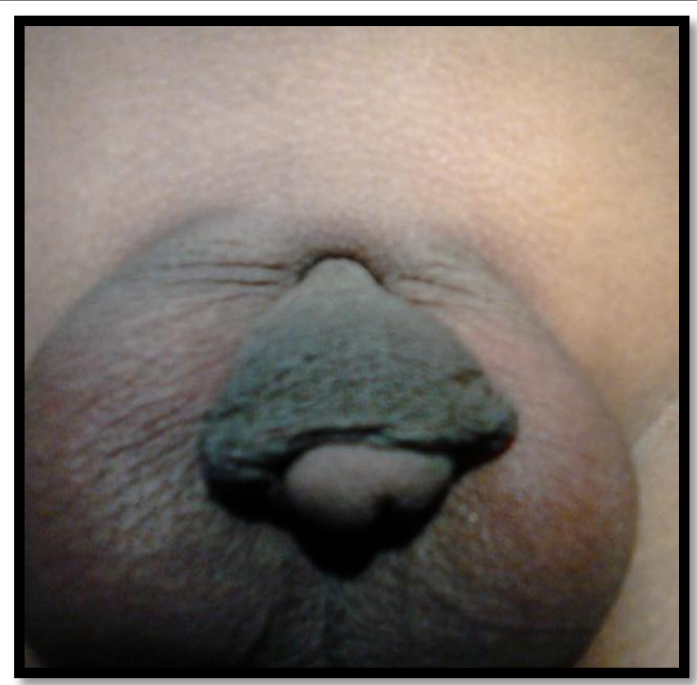

Figure 2 Varying degrees of severity of prepenile scrotum

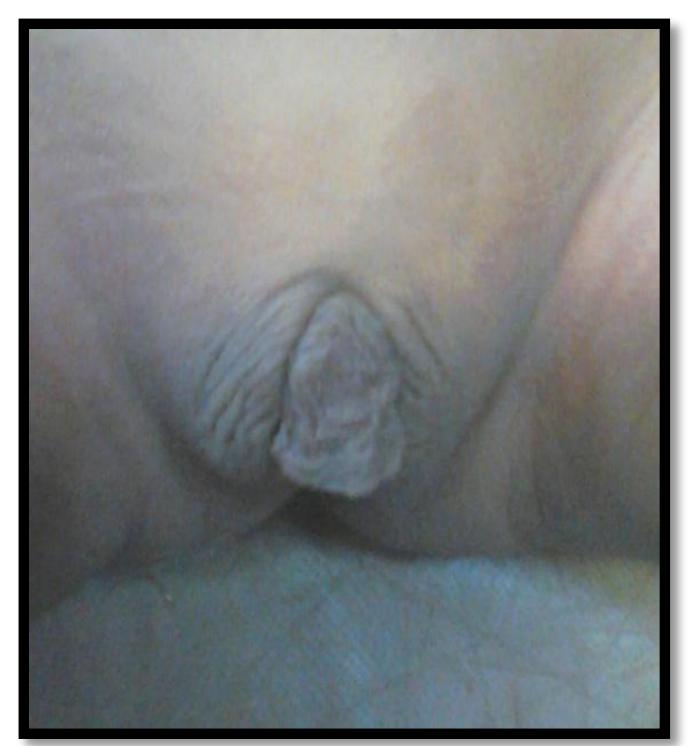

Figure 3 Varying degrees of severity of prepenile scrotum

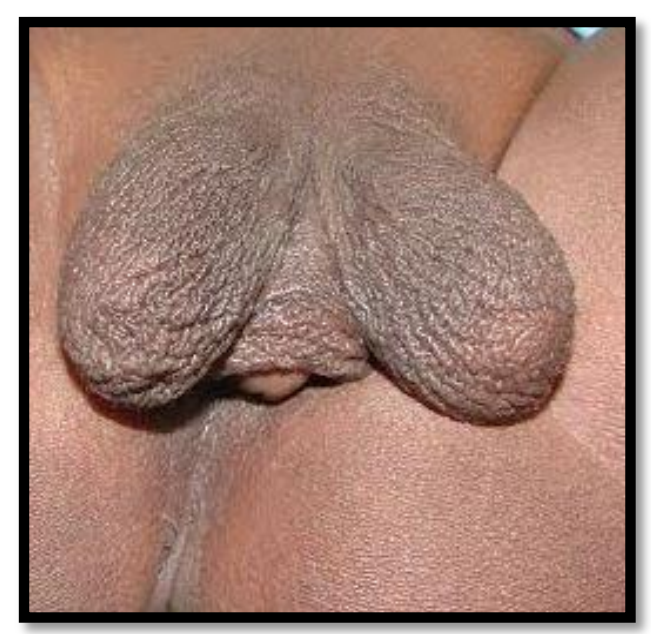

Figure 4 Varying degrees of severity of prepenile scrotum 


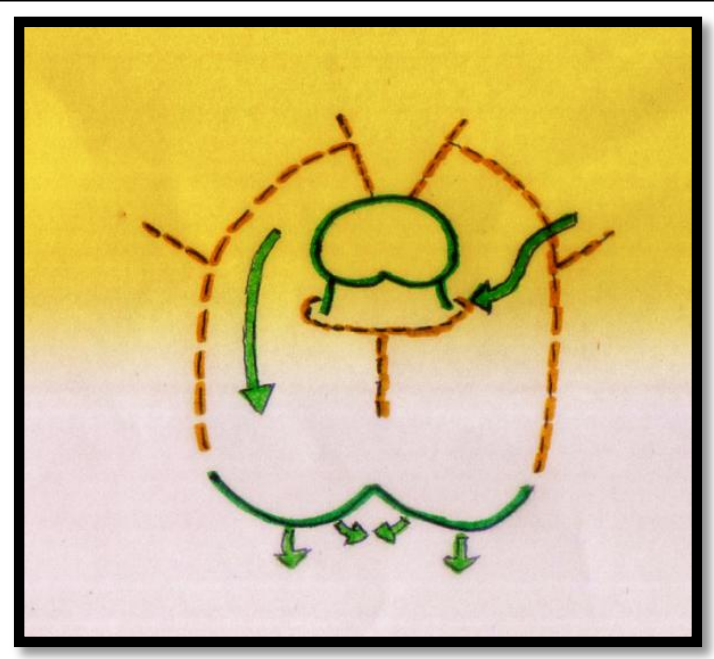

Figure 5 Glenn Anderson procedure for correction of prepenile scrotum

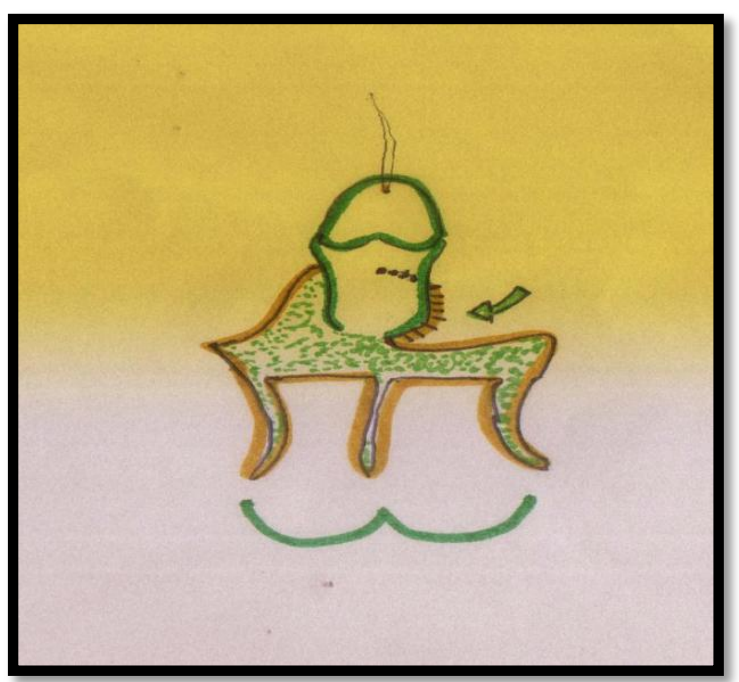

Figure 6 Glenn Anderson procedure for correction of prepenile scrotum

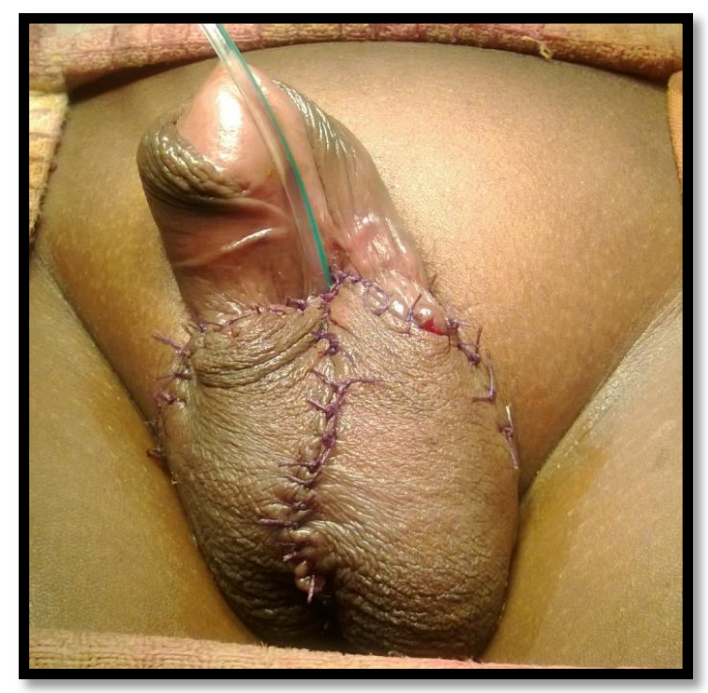

Figure 7 Post operative photograph after correction of prepenile scrotum

\section{Conclusions}

Correction by Glenn Anderson procedure, if combined along with chordee correction / urethroplasty carries high risk of complications including severe lymphedema, urethral and testicular injury.

There are unique constraints in performing correction of Pre penile scrotum which include difficulty to combine it with a Chordee correction or Urethroplasty, that includes a circumcoronal incision for degloving the penis, due to obvious deleterious effects on venous and lymphatic drainage of penile skin.

It is also difficult to assess chordee and meatus position with an uncorrected pre penile scrotum

There is also a high incidence of complications when correction of prepenile scrotum is combined with chordee correction/urethroplasty.

The repair of severe Hypospadias associated with prepenile scrotum, accomplished without correction of prepenile scrotum gives a poor cosmetic and functional outcome.

Separation of the rotation flaps by a small strip of dorsal skin helps decrease post operative lymphedema and skin complications.

The correction of severe Pre penile scrotum can be done as the preliminary procedure, prior to either staged or single stage urethroplasty. The incidence of complications is lesser when performed as staged, primary procedure.

\section{References}

1 Correction of Penoscrotal Transposition by Modified Glenn Anderson Technique Amin mM Saleh, Amr M Abdelatif, Amira Waly, Annals of Paediatric surgery, Vol 4, No 1,2,January-April 2008 PP14-17

2 Penosrotal Transposition with Hypospadias: One stage repair, Parovic S Vuadinovic V J Urol. 148:1510-13,1992

3 Surgical Correction of Incomplete Penoscrotal Transposition Glenn JF, Anderson EE. J Urol . 151:464, 1994 
4 Tubularized Incised Urethroplasty for diastal penile Hypospadias Snodgrass W J Uro. 151:464,1994

5 Trans Position of Penis and Scrotum: Case report. Mcllvoy DB, Harris HS. J Urol. 73:540-3,1955

6 Surgical Correction of Penoscrotal Transposition associated with hypospadias and Bifid Scrotum : Our experience of 2 stage repair. Arena F, Romeo C Managanaro A, et al. $\mathrm{J}$ of Pediat. Urol.1:289-94,2005

7 The Koyanagi- Nanomura 1 stage Ducket repair of severe Hypospadias with and without penoscrotal trans position Glassberg KI, Hansbrough F. Horowitz M. J Urol. 160:114-117, 1998.

8 Reconstruction of Penoscrotal Transposition Germiyanoglu C, Ozkardes H, Altug U et al. Br J Urol. 73:202-3,1994. 